\title{
Modification Of High Performance Training Algorithms for Solve Singularly Perturbed Volterra integro-differential and integral equation
}

\author{
Khalid. Mindeel. M. Al-Abrahemee \\ Department of Mathematics, College of Education / University of AL-Qadisiyha \\ Email: Khalid.mohammed@qu.edu.iq
}

Recived : 2\10\2018

Revised : 7\10\2018

Accepted : 14\10\2018

Available online : $\quad 21 / 10 / 2018$

DOI: $10.29304 / j q c m .2019 .11 .1 .448$

\begin{abstract}
:
In this paper, we apply neural network for solve singularly perturbed Volterra integrodifferential equations (SPVIDE) and singularly perturbed Volterra integral equations (SPVIE). Using Modification Of High Performance Training Algorithms such as quase-Newton, Levenberge-Marqaurdt, and Baysian Regulation. The proposed method was compared with the standard training algorithms and analytical methods. We found that the proposed method is characterized by high accuracy in the results, a lower error rate and a speed that is much convergent to standard methods.
\end{abstract}

Key words: Singularly perturbed Volterra integro-differential equations, Singularly perturbed Volterra integral equations, Singularly perturbed problems, neural network.

Mathematical subject classification : 34K28 


\section{Introduction:}

In this paper we consider the numerical discretization of (SPVIDE):

$$
\varepsilon \mho^{\prime \prime}(x) f\left(\mho, \mho^{\prime}, \mathcal{K}\right) \int_{0}^{x} \mathcal{M}(\mathcal{H}, t) \mho(t) d t, \mathcal{H} \in[a, b]
$$

with boundary condition $\mho(a)=A, \mho(b)=B$. And Volterra integral equations (SPVIE)

$\varepsilon \mho(x)=f(\mathcal{K})+\int_{0}^{x} \mathcal{M}(\mathcal{K}, t) \mho(t) d t \quad, \quad \mathcal{H} \in$ $[a, b]$

with boundary condition $\mho(a)=A, \mho(b)=B$, where $\varepsilon$ is a small parameter satisfying $0 \ll \varepsilon<1$ called perturbation parameter, $f$ and $\mathcal{M}$ are given.

An increasing interest in Voltaire's integrative and differential equations that have small parameters that stimulate this research. In the numerical solution to the problems of the value of the single hyper-limit of ordinary differential equations.

Nonlinear phenomena that appears in many applicationes in scientifec fields, such as fluids dynamics, solid state physics, plasma physics, mathematics biology and chemical, can be modeled by integral equations.. We are frequently faced with the problem of determining the solution of integral equations, one of these integral equations is SPVIE [1].

IN [2] have proposed the HPM for solving the SPVIEs, Alquran and Khair [3] solved the same problem by DTM and VIM. Finally, Dogan et al. [4] used DTM to solve the presented problem. Liao [5],[6],[7] successfully applied the HAM to solve many types of nonlinear problems.

This paper focus on building a new technique by using neural networks to arrive at an approximate solution to the integrated integrative and differential integrality equation. This structure of artificial neural networks (ANN) can calculate the corresponding production of vector inputs. The error function is now limited to the minimum in the selection points. Thus, the proposed ANN uses a training algorithm based on on quasi-Newton, Levenberg-Marquardt, and Bayesian Regulation algorithms used to modify the parameters (weights and biases) to any degree of accuracy required.

\section{Modification Of High Performance Training}

\section{Algorithms:}

In this section we will explicate how to modify some of the training algorithms. And to avoid some disadvantage that occurs in LM algorithm, we imply singular value decompation( $\mathrm{S}$ V D )of Jacobian matrix $\xi$ and $\xi^{-1}$ if $\xi(w)$ is a rectanguler matrix or singular, then we use SVD of $\xi(w)$. To avoid some disadvantage that occurs in of quasi- Newton algorithm, we explicate Singular Value Decomposition of Hessian matrix $\mathrm{Hand} \mathrm{H}^{-1}$, which is the mainly extensively use technique, and specially, it is a high-quality technique for illconditioned problems and to calculate the pseudoinverse ofH and to calculate theminimum error. To over passing the drawbackof BayesianRegulation algorithm, we imply S V D for compute $\xi$ and $\xi^{-1}$, which is a good quality technique to calculate the pseudoinverse of $\xi$ and to calculate the minimumerror.

\section{Description of the Method}

In this part we will explicate how our appear be able to use find the approximate solution of equations (1) and (2). To enter $\mathrm{y}(\mathrm{x})$ to the converter to be calculated, $\mho_{\tau}\left(\varkappa_{i}, \rho\right)$ Refers to the analytical solution. In the proposed approach, the FFNF experimental solution is used and the parameter $\mathrm{p}$ correspond to the $W_{i}$ and $B_{i}$ of the neural architecture. We choose a model for a pilot function $\mho_{\tau}(\mathcal{X})$ to meet $\mathrm{BC}$ requirements. This is acheived by writing it as two parts :

$\mho_{\tau}\left(\varkappa_{i}, \rho\right)=\mathrm{A}(\mathcal{H})+\mathcal{F}(\mathcal{H}, \mathbb{N}(\mathcal{K}, \rho, \varepsilon))(3)$ where $\mathbb{N}(\mathcal{H}, \rho, \varepsilon)$ is the output of the neural network with one input vector $\mathcal{H}$. 
Khalid.M

\section{Illustration of the Method}

To show the technique, we will consider the equations ((1) and (2)), where $\mathrm{x} \in[0,1]$ and the $\mathrm{BC}$ $\mho(0)=\mathrm{A}$ and $\mho(1)=\mathrm{B}$. The approximate solution can be written:

$$
\mho_{\tau}\left(\varkappa_{i}, \rho\right)=\mathrm{A}+(\mathrm{A}+\mathcal{B}) \varkappa+\varkappa(\varkappa-
$$
1) $\mathbb{N}(\mathcal{H}, \rho, \varepsilon)$
(4) , by

And the error quantety to be minimzed is given

$$
\begin{aligned}
& \qquad E[p]=\left\{\varepsilon \frac{d^{2} \mho_{\tau}}{d \mathcal{X}^{2}} \sum_{i=1}^{n} f\left(\mho_{i}, \mho_{t}^{\prime}, \mathcal{H}_{i}\right)+\right. \\
& \left.\int_{0}^{x} \mathcal{M}\left(\mathcal{H}_{i}, t\right) \mho_{\tau}(t) d t\right\}^{2}, \\
& \text { where the xi's are points in }[\mathrm{a}, \mathrm{b}] .
\end{aligned}
$$

\section{Numerical examples}

In this section we will present the numerical results of some mathematical models from the various examples of some cases of numerical conditions of the proposed neural network where the structure of the network consists of three layers. . In hidden layers we used sigmoid(logsig) as an activation function that is $\quad \sigma(\mathcal{X})=\frac{1}{1+e^{-\mathcal{X}}}$. or each test problem, the analytical solution $y_{a}(x)$ was defined in proceed. The accuracy of the approximate solutions can be tested by using the following equation $\quad \Delta \mho(x)=\mid \mho_{t}(\mathcal{X})-$ $\mho_{a}(x) \mid$.

In this section, there are three examples of different cases and each example contains four tables.

The first table shows the experimental and approximate solution of the high-level training algorithms with the analytical solution. The second table shows the error of the modified method and the third table represents the accuracy of the proposed method and the number of iterative needed to reach the target.

And the fourth table represents the initial value of $W_{i}$ and $B_{i} \mathrm{~s}$ of the of the neural network. The figure illustrates the exact and approximation solutions in the training set

\section{Example 1:}

We consider the following linear SPVIE [8]

$$
\begin{array}{rr}
\varepsilon y(x)=\int_{0}^{x}[1+t-y(t) d t \quad \text { and } \mathrm{BC}: \\
\mathrm{y}(0)=0 \quad, \mathrm{y}(1)=y(x)=2-e^{-\frac{1}{\varepsilon}}-\varepsilon\left(1-e^{-\frac{1}{\varepsilon}}\right)
\end{array}
$$

which has the exact solution $y(x)=x+1-$ $e^{-\frac{x}{\varepsilon}}-\varepsilon\left(1-e^{-\frac{x}{\varepsilon}}\right), \varepsilon=0.25$.

\section{Example 2:}

We consider the following nonlinear SPVIE [9]

$y(x)=\frac{1}{\varepsilon}\left(1-e^{x}\right)+\frac{1}{\varepsilon} \int_{0}^{x} e^{x-t} y^{2}(t) d t$

and the boundary conditions $\mathrm{y}(0)=0$,

$$
\mathrm{y}(1)=\frac{2\left(1-e^{\frac{1}{\varepsilon}\left(\sqrt{1+4 \varepsilon^{2}}\right)}\right.}{\varepsilon\left(\frac{1}{\varepsilon}\left(\sqrt{1+4 \varepsilon^{2}}\right)-1\right) e^{\frac{1}{\varepsilon}\left(\sqrt{1+4 \varepsilon^{2}}\right)}+\frac{1}{\varepsilon}\left(\sqrt{1+4 \varepsilon^{2}}\right)+1}
$$

which has the exact solution $y(x)=$ $\frac{2\left(1-e^{\varphi x}\right)}{\varepsilon(\varphi-1) e^{\varphi x}+\varphi+1}$

where the parameters $\varphi$ are defined as $\varphi=\frac{1}{\varepsilon}\left(\sqrt{1+4 \varepsilon^{2}}\right)$ and $\varepsilon=0.75$.

\section{Example 3:} 12]

In this problem we consider the SPVIDE [10-

$\varepsilon \frac{d}{d x} y(x)=(1+\varepsilon) e^{-1}-\varepsilon-y(x)+\int_{0}^{x}(1+$

$\varepsilon) y(t) d t$

with the boundary condition $y(0)=1+e^{-1}$, $y(1)=1+e^{\frac{-1}{\varepsilon(1+\varepsilon)}}$ and the analytic solution is $y(x)=e^{x-1}+e^{\frac{-x}{\varepsilon(1+\varepsilon)}}$, we get $\varepsilon=2^{-10}$.

\section{Conclusion}

This paper present new technique to solve $2^{\text {nd }}$ singularly perturbed Volterra integro-differential equations (SPVIDE) and singularly perturbed Volterra integral equations (SPVIE). Using artificial neural network which have the singularly perturbed, using modification of high performance training algorethms such as quase-Newton, LevenbergeMarquard, and Baysian Regulation. The projected construction of ANN is more professional and accurate than the other approximat method. convenient outcome with a few hundred wieghts prove that the Levenberge-Marquardt (trainlm) algorethm will have the highest convergence, then trainbfg and trainbr. The performance of different algorethms can be affect by the accuracyrequired for rounding. 


\section{References :}

[1] M.H. Alnasr. Numerical treatment of singularly perturbed volterra integral equations, Ph.D thesis, Egypt, 1997.

[2] M.H. Alnasr, S. Momani. Application of homotopy perturbation method to singularly perurbed volterra integral equations. J. Appl. Sci, 8(2008): 1073-1078.

[3] M. Alquran, B. Khair. Algorithms to solve singularly perturbed volterra integral equations. Appl. Appl. Math, 6(2011): 2110-2124.

[4] N. Dogan, V. Erturk, S. Momani, O. Akin, A. Yildirim. Differential transform method for solving singularly perturbed volterra integral equations. J. King Saud Univ. Sci, 23(2011): 223-228.

[5] S. J. Liao. Beyond perturbation: Introduction to homotopy analysis method, Chapman \& Hall/CRC Press, Boca Raton, 2003.

[6] Hristev, R. M. ," The ANN Book ", Edition 1, 1998.

[7] Yamashita N., Fukushima M., "On the rate of convergence of the Levenberg-Marquardt method", Computing Suppl. J., Vol. 15,(2001), pp: 237-249.

[8] M.H.Alnaser, Shaher Momani, “Application of Homotopy Perturbation Metood to Singularly Perturbed Volterra Integral Equation" 8(6) (2008):1073-1078.
[9] Ahmad Jafarian, Pariya Ghaderi," Application of Homotopy Analysis Method for the Singularly Perturbed Volterra Integral Equations", 7(1) 2013,: 41-54.

[10] V. Horvat and M. Rogina. Tension spline collocation methods for singularly perturbed Volterra integro-differential and Volterra integral equations. J. Comput. Appl. Math., 140(2002):381402.

[11] A. Salama and S.A. Bakr. Difference schemes of exponential type for singularly perturbed Volterra integrodifferential problems. Appl. Math. Model., 31(2007):866-879.

[12] J.I. Ramos. Piecewise-quasilinearization techniques for singularly perturbed Volterra integrodifferential equations.Appl. Math. Comput., 188(2007):1221-1233.

[13] K. Parand , J.A. Rad," An Approximation Algorithm for the Solution of the Singularly Perturbed Volterra Integro-differential and Volterra Integral Equations", Vol.12(2011):430-441.

Table 1: presents a comparison between the exact and approximated solutions of example $1, \varepsilon=0.25$

\begin{tabular}{|c|c|c|c|c|}
\hline input & Analytic solution & \multicolumn{2}{|c|}{ Solution of FFNN yt $(\boldsymbol{x})$ for training algorithm } \\
\hline $\boldsymbol{x}$ & $y a(\boldsymbol{x})$ & Trainlm & Trainbfg & Trainbr \\
\hline 0.0 & 0 & $8.63846704779123 \mathrm{e}-06$ & $6.24160951957431 \mathrm{e}-06$ & $3.33127199026609 \mathrm{e}-06$ \\
\hline 0.1 & 0.347259965473271 & 0.347262822894421 & 0.347549233468808 & 0.347241687278199 \\
\hline 0.2 & 0.613003276912084 & 0.613012683806799 & 0.612995182065023 & 0.613047107476904 \\
\hline 0.3 & 0.824104341065849 & 0.823855506383785 & 0.824088405150215 & 0.824059458872570 \\
\hline 0.4 & 0.998577611504008 & 0.998385206583588 & 0.998584506284787 & 0.998578563013621 \\
\hline 0.5 & 1.14849853757254 & 1.14847942445457 & 1.14848027740797 & 1.14853704015194 \\
\hline 0.6 & 1.28196153503294 & 1.28199362598582 & 1.28192438254163 & 1.28193562817729 \\
\hline 0.7 & 1.40439245303109 & 1.40437009337511 & 1.40437701556679 & 1.40428258136672 \\
\hline 0.8 & 1.51942834701623 & 1.51937926612973 & 1.51943739391913 & 1.51933087735538 \\
\hline 0.9 & 1.62950720816453 & 1.62950369108927 & 1.62944608756291 & 1.62951250794293 \\
\hline 1.0 & 1.73626327083345 & 1.73621733919038 & 1.73591117829189 & 1.73626101112071 \\
\hline
\end{tabular}

Table 2: Accuracy of solutions of example 1

\begin{tabular}{|c|c|c|}
\hline \multicolumn{2}{|c|}{ The error $E(x)=|y t(x)-y a(x)|$ where $y t(x)$ computed by the followin } \\
training algorithm
\end{tabular}


Khalid.M

Table 3: The accuracy of the train of suggested FFNN,

\begin{tabular}{|c|c|c|c|c|}
\hline Train function & Performance of train & Epoch & Time & Msereg. \\
\hline Trainlm & $3.09 \mathrm{e}-33$ & 95 & $0: 00: 01$ & $8.634742679417933 \mathrm{e}-09$ \\
\hline Trainbfg & $1.60 \mathrm{e}-15$ & 442 & $0: 00: 08$ & $1.749442398773895 \mathrm{e}-08$ \\
\hline Trainbr & $7.19 \mathrm{e}-10$ & 301 & $0: 00: 04$ & $2.294226818490657 \mathrm{e}-09$ \\
\hline
\end{tabular}

Table 4: Initial weight and bias of FFNN

\begin{tabular}{|c|c|c|c|c|c|c|c|c|}
\hline \multicolumn{3}{|c|}{$\begin{array}{c}\text { Initial weights and bias } \\
\text { for trainlm }\end{array}$} & \multicolumn{3}{|c|}{$\begin{array}{c}\text { Initial weights and bias } \\
\text { for trainbfg }\end{array}$} & \multicolumn{3}{|c|}{$\begin{array}{c}\text { Initialweights and bias } \\
\text { for trainbr }\end{array}$} \\
\hline $\begin{array}{l}\text { Net.IW } \\
\{1,1\}\end{array}$ & $\begin{array}{l}\text { Net.LWW } \\
\{2,1\}\end{array}$ & \begin{tabular}{|c|} 
Net.B $B\{1$ \\
\} \\
\end{tabular} & $\begin{array}{l}\text { Net.IW } \\
\{1,1\}\end{array}$ & $\begin{array}{l}\text { Net.LWW } \\
\{2,1\}\end{array}$ & $\begin{array}{c}\text { Net.B }\{1 \\
\}\end{array}$ & $\begin{array}{l}\text { Net.IW } \\
\{1,1\}\end{array}$ & $\begin{array}{l}\text { Net.LWW } \\
\{2,1\}\end{array}$ & $\begin{array}{c}\text { Net.B } B\{1 \\
\}\end{array}$ \\
\hline 0.2691 & 0.9831 & 0.6981 & 0.7702 & 0.1759 & 0.6074 & 0.5523 & 0.0495 & 0.1465 \\
\hline 0.4228 & 0.3015 & 0.6665 & 0.3225 & 0.7218 & 0.1917 & 0.6299 & 0.4896 & 0.1891 \\
\hline 0.5479 & 0.7011 & 0.1781 & 0.7847 & 0.4735 & 0.7384 & 0.0320 & 0.1925 & 0.0427 \\
\hline & 0.6663 & 0.1280 & & 0.1527 & 0.2428 & & 0.1231 & 0.6352 \\
\hline 0.4177 & 0.5391 & 0.9991 & 0.0358 & 0.3411 & 0.9174 & 0.3624 & 0.2055 & 0.2819 \\
\hline
\end{tabular}

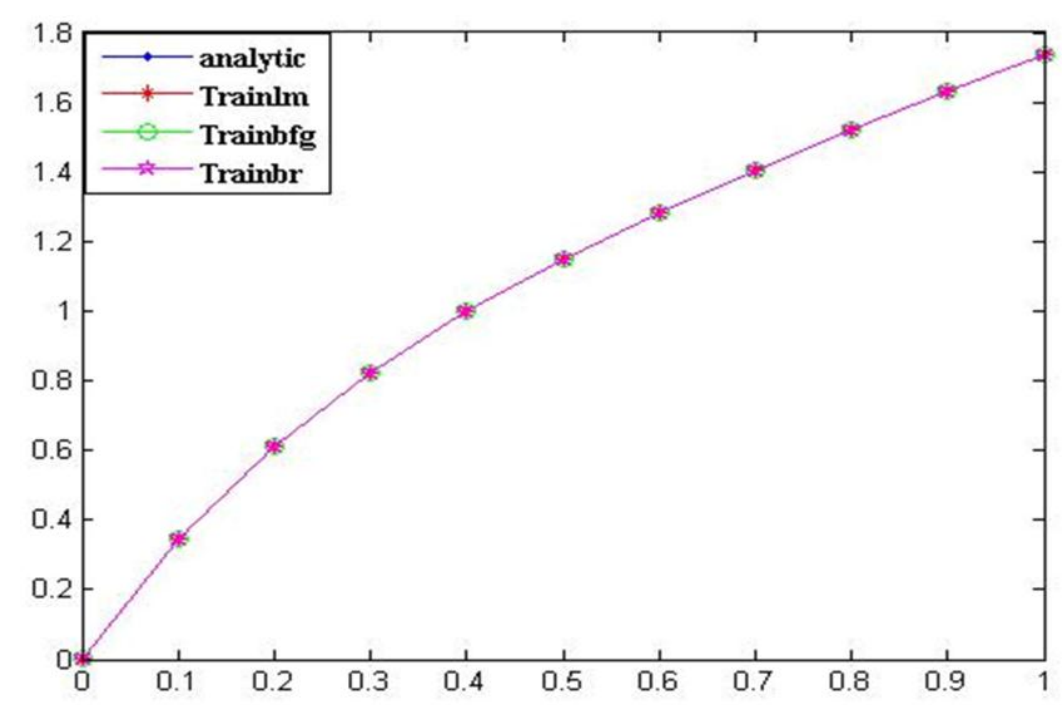

Figure(1) : shows a comparison between the exact solution and the appro $\times$ imate solution of the problem which is presented in example 1 , with $\varepsilon=0.25$. 
Table 5: : presents a comparison between the exact and approximated solutions of example $2, z=0.75$

\begin{tabular}{|c|c|c|c|c|}
\hline input & Analytic solution & \multicolumn{3}{|c|}{ Solution of FFNN $\mathrm{x}_{\mathrm{t}}(\mathrm{x})$ for training algorithm } \\
\hline$x$ & $y_{2}(x)$ & Trainlm & Trainbfg & Trainbr \\
\hline 0.0 & 0 & $-1.23296639564785 e-09$ & $-2.29553043240571 \mathrm{e}-10$ & $-6.76384614983760 e-09$ \\
\hline 0.1 & -0.129682372351998 & -0.129682372416046 & -0.129682331724809 & -0.129682382846623 \\
\hline 0.2 & -0.279753006539272 & -0.279753006437191 & -0.279753106383285 & -0.279753010727454 \\
\hline 0.3 & -0.448074072192466 & -0.448074072225477 & -0.448074029369055 & -0.448074072108653 \\
\hline 0.4 & -0.630374312628864 & -0.630374312671338 & -0.630374165443910 & -0.630374312666036 \\
\hline 0.5 & -0.820483778242515 & -0.820483778253259 & -0.820483734588987 & -0.820483779223842 \\
\hline 0.6 & -1.01107274618158 & -1.01107274623763 & -1.01107281604895 & -1.01107274632745 \\
\hline 0.7 & -1.19473797678062 & -1.19473797682557 & -1.19473800796783 & -1.19473797555232 \\
\hline 0.8 & -1.36511190858948 & -1.36511190848251 & -1.36511196236237 & -1.36511190753393 \\
\hline 0.9 & -1.51765877577841 & -1.51765877584827 & -1.51765912453648 & -1.51765877552818 \\
\hline 1.0 & -1.64997435974891 & -1.64997436156016 & -1.64997435305496 & -1.64997435715362 \\
\hline
\end{tabular}

Table 6: Accuracy of solutions of example $2, z=0.75$

\begin{tabular}{|c|c|c|}
\hline \multicolumn{3}{|c|}{ The error $E(x)=\mid \begin{array}{c}y t(x)-y a(x) \mid \text { where } y t(x) \text { computed by } \\
\text { the following training algorithm }\end{array}$} \\
\hline Trainlm & Trainbfg & Trainbr \\
\hline $1.23296639564785 \mathrm{e}-09$ & $2.29553043240571 \mathrm{e}-10$ & $6.76384614983760 \mathrm{e}-09$ \\
\hline $6.40480168900837 \mathrm{e}-11$ & $4.06271892516852 \mathrm{e}-08$ & $1.04946255297111 \mathrm{e}-08$ \\
\hline $1.02081509911756 \mathrm{e}-10$ & $9.98440130017819 \mathrm{e}-08$ & $4.18818218994588 \mathrm{e}-09$ \\
\hline $3.30114824365069 \mathrm{e}-11$ & $4.28234107063830 \mathrm{e}-08$ & $8.38128455526999 \mathrm{e}-11$ \\
\hline $4.24735802084797 \mathrm{e}-11$ & $1.47184954446544 \mathrm{e}-07$ & $3.71715991320798 \mathrm{e}-11$ \\
\hline $1.07445163877173 \mathrm{e}-11$ & $4.36535279035866 \mathrm{e}-08$ & $9.81327130666898 \mathrm{e}-10$ \\
\hline $5.60449464614976 \mathrm{e}-11$ & $6.98673674470740 \mathrm{e}-08$ & $1.45869538670240 \mathrm{e}-10$ \\
\hline $4.49544845793071 \mathrm{e}-11$ & $3.11872150327019 \mathrm{e}-08$ & $1.22829435511562 \mathrm{e}-09$ \\
\hline $1.06969100244214 \mathrm{e}-10$ & $5.37728923610814 \mathrm{e}-08$ & $1.05554631701921 \mathrm{e}-09$ \\
\hline $6.98625601813774 \mathrm{e}-11$ & $3.48758070423116 \mathrm{e}-07$ & $2.50229170717375 \mathrm{e}-10$ \\
\hline $1.81124848452896 \mathrm{e}-09$ & $6.69394806251944 \mathrm{e}-09$ & $2.59529575608042 \mathrm{e}-09$ \\
\hline
\end{tabular}

Table 7:The accuracy of the train of suggested FFNN, $\varepsilon=0.75$

\begin{tabular}{|c|c|c|c|c|}
\hline Train function & Performance of train & Epoch & Time & Msereg. \\
\hline Trainlm & $5.03 \mathrm{e}-21$ & 225 & $0: 00: 02$ & $3.959872612109448 \mathrm{e}-19$ \\
\hline Trainbfg & $1.60 \mathrm{e}-15$ & 442 & $0: 00: 08$ & $1.370004135922276 \mathrm{e}-14$ \\
\hline Trainbr & $8.19 \mathrm{e}-18$ & 286 & $0: 00: 03$ & $1.504156882367969 \mathrm{e}-17$ \\
\hline
\end{tabular}

Table 8: Initial weight and bias of FFN,, $2=0.75$

\begin{tabular}{|c|c|c|c|c|c|c|c|c|}
\hline \multicolumn{3}{|c|}{$\begin{array}{c}\text { Initial weights and bias } \\
\text { for trainlm }\end{array}$} & \multicolumn{3}{|c|}{$\begin{array}{c}\text { Initial weights and bias } \\
\text { for trainbfg }\end{array}$} & \multicolumn{3}{|c|}{$\begin{array}{c}\text { Initialweights and bias } \\
\text { for trainbr }\end{array}$} \\
\hline Net.IW & Net.LW & Net. $B\{1$ & Net.IW\} & Net. LW & Net. $B\{1$ & Net.IW\} & Net.LW & Net. B $\{1$ \\
\hline 0.1478 & 4674 & 0 & 0. & 0 & 62 & 0 & 0.6714 & 0.2794 \\
\hline 0.0198 & 0.6567 & 0.2672 & 0.4736 & 0.5876 & 0.4679 & 0.6866 & 0.8372 & 0.9462 \\
\hline 0.9643 & 0.2902 & 0.7537 & 0.9497 & 0.8776 & 0.8608 & 0.7194 & 0.9715 & 0.9064 \\
\hline 0.9704 & 0.7545 & 0.8984 & 0.0835 & 0.4691 & 0.4665 & 0.6500 & 0.0569 & 0.3927 \\
\hline 0.1239 & 0.5581 & 0.7284 & 0.2798 & 0.4374 & 0.4981 & 0.7269 & 0.4503 & 0.0249 \\
\hline
\end{tabular}


Khalid.M

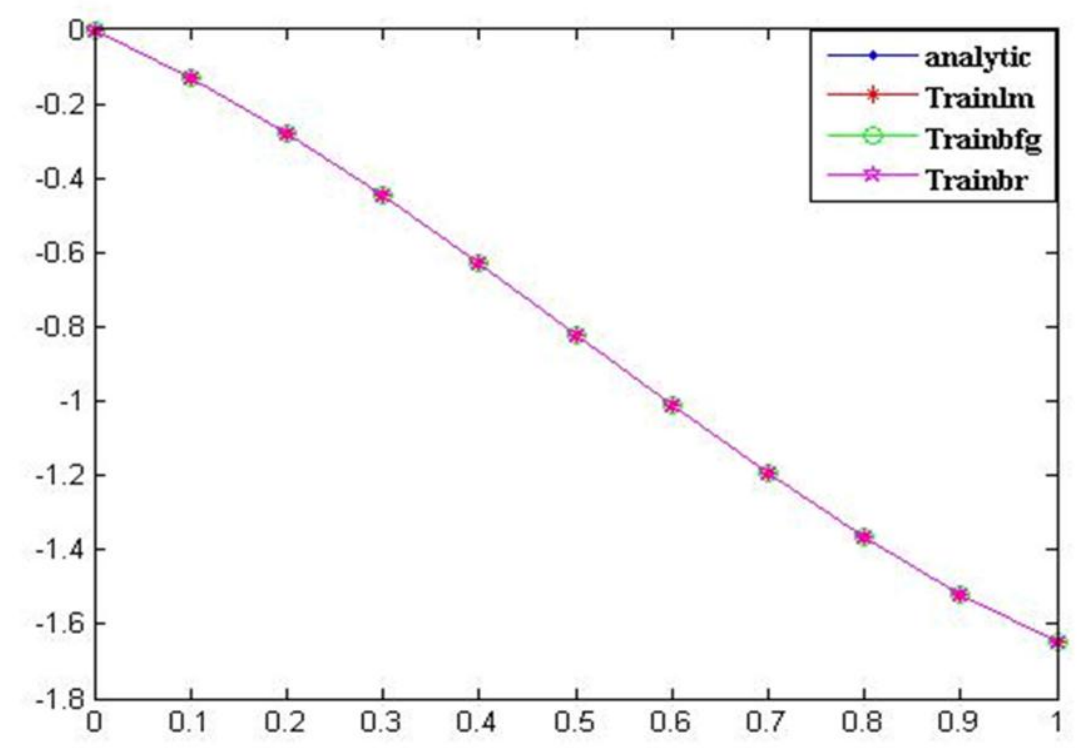

Figure2: shows a comparison between the e $\times$ act solution and the appro $\times$ imate solution of the problem which is presented in example 2, with $\varepsilon=0.75$.

Table 9: presents a comparison between the exact and approximated solutions of example $3,2=10^{-6}$

\begin{tabular}{|c|c|c|c|c|}
\hline input & Analytic solution & \multicolumn{3}{|c|}{ Solution of FFNN yt $(x)$ for training algorithm } \\
\hline$x$ & $y a(x)$ & Trainlm & Trainbfg & Trainbr \\
\hline 0.0 & 1.36787944117144 & 1.36788008912683 & 1.36658579902398 & 1.36787348745286 \\
\hline 0.1 & 0.408403141605383 & 0.408403158192725 & 0.409648772717205 & 0.408555958854668 \\
\hline 0.2 & 0.449332325772970 & 0.447220714806900 & 0.446917028590653 & 0.449072090350214 \\
\hline 0.3 & 0.4965853099549444 & 0.496585884132547 & 0.497291215677891 & 0.496705926669505 \\
\hline 0.4 & 0.548811636105327 & 0.549525400628744 & 0.550290995079382 & 0.548833632292113 \\
\hline 0.5 & 0.606530659712654 & 0.606598111288221 & 0.607065207795657 & 0.605991033696597 \\
\hline 0.6 & 0.670320046035639 & 0.670332186873078 & 0.669343251141215 & 0.669735307851162 \\
\hline 0.7 & 0.740818220681718 & 0.740783737266799 & 0.739191349597689 & 0.744369056450970 \\
\hline 0.8 & 0.818730753077982 & 0.818759261704545 & 0.818267940190760 & 0.818711070837418 \\
\hline 0.9 & 0.904837418035960 & 0.904826537817461 & 0.905932626518221 & 0.904812403869590 \\
\hline 1.0 & 1 & 0.999131812534284 & 0.998764074542181 & 1.00337320163045 \\
\hline
\end{tabular}

Table 10: Accuracy of solutions of example $3,2=10^{-6}$

\begin{tabular}{|c|c|c|}
\hline \multicolumn{3}{|c|}{ The error $E(x)=|y t(x)-y a(x)|$ where $y t(x)$ computed by the } \\
following training algorithm
\end{tabular}


Journal of AL-Qadisiyah for computer science and mathematics Vol.11 No.1 Year 2019 ISSN (Print): 2074 - $0204 \quad$ ISSN (Online): 2521 - 3504

Khalid.M

Table 11: The accuracy of the train of suggested FFNN, $z=10^{-6}$

\begin{tabular}{|c|c|c|c|c|c|}
\hline Train function & Performance of train & Epoch & Time & Msereg. & $\begin{array}{c}\text { MSE of Numerical } \\
\text { Method in } \\
{[13]}\end{array}$ \\
\hline Trainlm & $3.24 \mathrm{e}-10$ & 369 & $0: 00: 06$ & $4.687304918869537 \mathrm{e}-07$ & \multirow{2}{*}{$8.70 e-003$} \\
\hline Trainbfg & $7.84 \mathrm{e}-8$ & 209 & $0: 00: 03$ & $1.519637055012368 \mathrm{e}-06$ & \\
\hline Trainbr & $1.20 \mathrm{e}-22$ & 275 & $0: 00: 04$ & $2.023134155861496 \mathrm{e}-06$ & \\
\hline
\end{tabular}

Table 12: Initial weight and bias of FFNN, $z=10^{-6}$

\begin{tabular}{|c|c|c|c|c|c|c|c|}
\hline \multicolumn{2}{|c|}{$\begin{array}{c}\text { Initial weights and bias } \\
\text { for trainlm }\end{array}$} & \multicolumn{3}{c|}{$\begin{array}{c}\text { Initial weights and bias } \\
\text { for trainbfg }\end{array}$} & \multicolumn{2}{c|}{ Initialweights and bias } \\
for trainbr
\end{tabular}

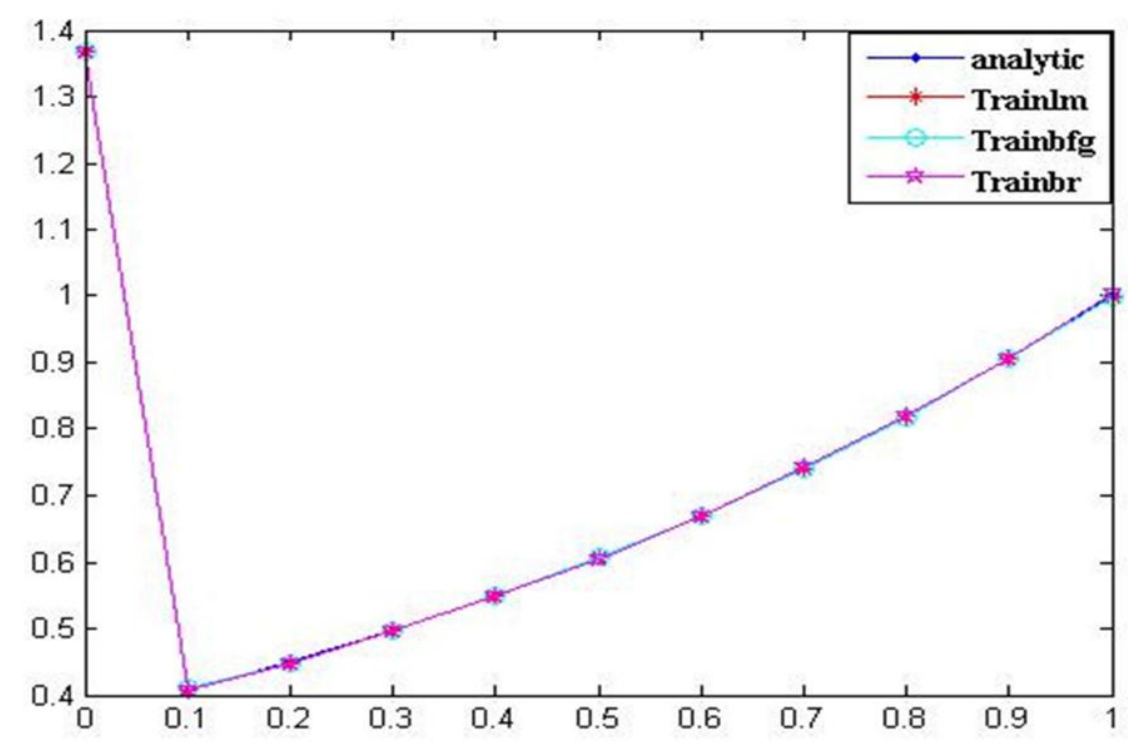

Figure 3.: shows a comparison between the exact solution and the appro $\times$ imate solution of the problem which is presented in example 3 , with $\varepsilon=2^{-6}$. 
خوارزميات التدريب ذات الاداء العالي المحسنة لحل معادلة فولتيرا التكاملية التفاضلية و التكاملية المضطربة الماذة الشئة

$$
\text { قسم الرياضيات ـ كلية التربية - جامعدة القادسية }
$$

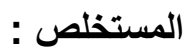

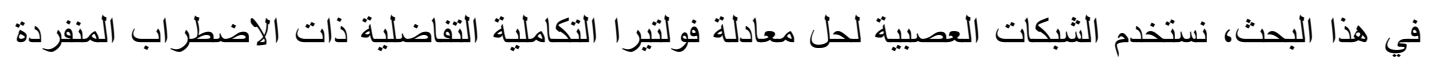

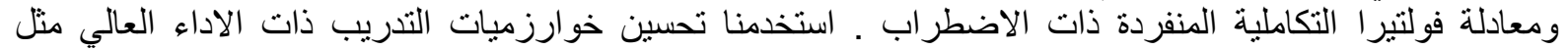

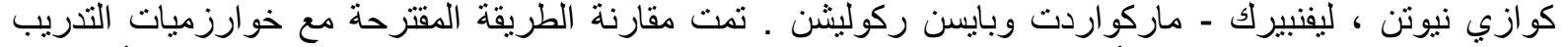

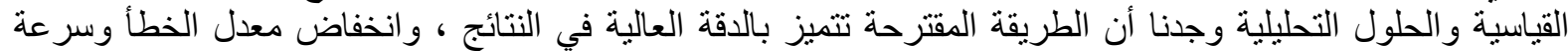
التقارب كثيرًا مع الطرق القياسية . 